curiosity since few of the audience realized that there were any. Dr. A. E. Moodie, a geographer of Birkbeck College, London, presented to zoologists and geologists an account of the evolution of international law relating to the sovereignty of coastal States over the continental shelf. Though the implications were clear enough, the story seemed as unreal as that of a comic opera and could have no place in a discussion on natural science. [See also p. 1063 of this issue of Nature.]

Since 1939, and especially since 1945, there has been a spate of claims to exercise sovereignty over the shelf, especially by American Republics. The United Kingdom has been party with Venezuela to a division of the Gulf of Paria. Motives have been twofold: the search for oil and the attainment of security. Many unilateral claims have been extravagant, and the legal position was becoming chaotic. In 1948, therefore, the General Assembly of the United Nations recommended to the International Law Commission that it should give priority to discussions on the regime of the high seas. After five years of argument and counter-argument, the Commission has agreed to recognize in principle qualified sovereign rights of a coastal State over the adjacent part of the shelf. It does not follow that the General Assembly will accept them.

The latest information available to Dr. Moodie was United Nations Press Release L/47, dated July
17, 1953, while the jurists were still sitting. The draft articles in full with an extended commentary were published on August 17 as United Nations General Assembly $A / C N .4 / 76$, pp. 35-56. This document shows that the Commission recommends that all contiguous waters shall be divided into two zones : the territorial sea, broadly equivalent to the present concept of territorial waters extending from the coast for three or some other number of miles to seaward; and the continental shelf, extending from the limit of the territorial sea to a depth of $200 \mathrm{~m}$. The major difference in legal status will be that within the territorial sea the coastal State exercises, as previously, complete sovereignty over sea-floor, subsoil and superjacent waters, whereas over the continental shelf the superjacent waters and airspace will not be subject to the sovereignty of the coastal State. Over the whole of the continental shelf the coastal State will exercise sovereignty over the exploration and exploitation of the sea-bed and subsoil, just as it does over its land territory. The extension of the seaward boundaries of a coastal State to the $200-\mathrm{m}$. contour means a very great extension of the State's authority and could in some circumstances become a grave hindrance not only to trade and fishing but also to scientific research. Juridical problems, affecting the freedom of marine research, may arise when two or more States lie adjacent to the same continental shelf.

\title{
XIX INTERNATIONAL PHYSIOLOGICAL CONGRESS, MONTREAL
}

$\mathrm{T}$ HE XIX International Physiological Congress was opened in the Sir Arthur Currie gymnasium of McGill University, Montreal, on Monday, August 31 , 1953, at 5 p.m., by the president, Prof. C. H. Best, of the University of Toronto. The platform party made an imposing entry to the large gym. nasium filled with more than two thousand members of the Congress, who stood in respect as their senior colleagues, together with the dignitaries of Montreal and of Quebec Province, passed along the centre aisle. This impressive stage-management was characteristic of the superb efficiency with which the local organizing committee, ably led-and perhaps driven - by Prof. F. C. MacIntosh, of McGill University, had organized the whole of this vast Congress.

Following the official opening of the Congress, the remainder of this plenary session consisted of speeches of welcome from Dr. J. B. Collip, president of the Canadian Physiological Society, which was the host organization to the Congress; from Dr. F. C. James, principal of McGill University, on behalf both of MeGill University and of the University of Montreal ; from Mayor Camillien Houde, on behalf of the city of Montreal ; and from Dr. G. D. W. Cameron, deputy minister of health, on behalf of the Government of Quebec. The president of the Congress conveyed the thanks of all members to the many host organizations, in a large variety of languages, including Iroquois; in fact, the linguistic attainments of the platform party were astonishing, from Dr. Collip's speech in French, onwards; but the thunder of the whole session was stolen by Mayor Houde, whose memorable address made even vital statistics vital. Shortly before the close of the meeting, Dr. E. D. Adrian, of the University of Cambridge, outlined the plan of the Permanent Committee, of which he is president, for the establishment of an International Union of Physiological Sciences, and promised members that the Permanent Committee at least intended to work during the Congress-and hoped to present the final recommendations at the closing plenary session. The entire concourse then made its way very slowly up a steep hill to Forbes Field, where, in the open air, all were entertained at the hands of the Provincial Government of Quebec. This reception was memorable, not only for being held in such pleasant surroundings, not only for the unrivalled opportunities for meeting, for the first time, many of one's fellow members, not only for the generous spirit of the Government of Quebec, but also for a buffet which broke all records in running out of soft drinks and sodawater only. In this way then did August fade away, and on the first of September members were faced with a staggering programme of scientific sessions, and the technical work of the Congress began.

It is said in North America that only the English can talk uninterruptedly for longer than thirty seconds about the weather; but all racial records were broken in Montreal, where, despite the unparalleled opportunities for 'shop', the climate must surely have taken pride of place as a subject for discussion. The Congress basked or baked in temperatures that seldom-or was it ever?--fell out of the 90 's, and members were little comforted by the repeated assurances of the 'locals' that this was most unusual for the time of the year. Recollection of sessions in hot and crowded lecture halls will remain long after memory of the scientific proceedings has faded; but more comfortable recol- 
lections of the ample standing, seating and lying accommodation will also linger.

There were some 2,750 registrations in all, more than two thousand being full members of the Congress. There were eight symposia, eighteen films, fifty-eight demonstrations and 792 communications. This programme was completed in a total of seven half-day sessions, and there were never fower than fourteen nor more than seventeen concurrent activities. This report must therefore be selective and must inevitably show bias in referring mainly to work in one major field of interest; it is proposed to mention only a few points of interest from the 792 communications and to describe briefly the subject-matter of the symposia.

The organization of an international meeting of this magnitude throws an indescribable burden of work on the scientific personnel of the host country and, even more, of the host city. One is inevitably left reflecting whether it is worth the labour, or whether some alternative plan for the Congress would not ease the load. The idea of more frequent, small-scale international symposia is attractive and is becoming more and more a feature of scientific discussion nowadays; but they can only serve as an adjuvant to the full Congress. Let us therefore accept the restrictions and the inevitable frustrations of the large-scale meeting, and agree that only at such a meeting can one meet and talk with those in wholly different fields of work; more can be learned in private conversations than in formal lecture halls.

First, in the neurophysiological field, R. Stämpfli (Berne) has introduced a 'simple' method for measuring membrane potentials and, as a result, we may find that, in the future, even the old-school pharmacologists will indulge in talk of "resting potentials".

V. B. Brooks (Montreal) provided a beautifully logical exposition of the action of Botulinus toxin in blocking conduction in the fine nonmyelinated terminal filaments of motor nerves. This has long been assumed but never before so adequately proved.

A. von Muralt (Berne) has further enlarged the neurophysiological vocabulary with 'stroboscopic photochemistry' and, with elegant technique, has shown that light at various optimal wave-lengths can greatly influence the threshold of a single nerve fibre. The changes depend on the time relationship between the light flash and the electrically excited action-potential; and on whether the flash is directed on a node of Ranvier or on an internode. Light of wave-length $280 \mathrm{~m} \mu$ can inactivate enzymes which may play a part in the chemical reactions providing the free energy for the maintenance of excitability.

It was a pity that A. V. Kibjakow (Kazanj, U.S.S.R.) was not present to read his paper (read by title only), for the abstract is rnost stimulating. In particular, it is interesting to note that he finds that chronic pancreatectomy reduces the output of acetylcholine from cholinergic nerve-endings. $\mathrm{He}$ has resisted the obvious temptation to speculate as to the reason for this observation, except to attribute it to a disturbance of phospholipid metabolism. He proceeds, however, to discuss in considerable detail the function of the animal thus partially deprived of one of the mediators of nervous transmission, and further open discussion of this question might have been most enlightening.
H. Konzett and E. Rothlin (Basle) settled one outstanding query in connexion with the effects of denervating an organ when they showed that neither the increased sensitivity of ganglion cells to acetylcholine nor the depletion of cholinesterase in the ganglion-both of which are found after denervation-is obtained after long-term block of ganglion transmission with a ganglion-blocking drug. Thus, the 'trophic' effect exerted by the intact pre-ganglionic fibres cannot be dependent upon constant reaction of the cells to the normal transmitter.

E. M. Vaughan Williams and S. W. Kuffler (Oxford and Baltimore) have most ingeniously devised a means of recording both 'fast' or 'twitch' and 'slow' striated muscle fibres in the frog rectus muscle, and have shown that the muscle responds to acetylcholine by a contracture due to activation of the 'slow' muscle fibres only, the 'twitch' fibres relaxing rapidly in the acetylcholine solutions. It appears that no muscle fibres have a double innervation, the 'slow' fibres being innervated by small-diameter nerves only. This work has gone far towards resolving the nature of the system used, in ignorance, for so long as a routine pharmacological test for acetylcholine activity.

R. H. Beutner (Little Rock, U.S.A.) and T. C. Barnes (Philadelphia) discussed artificial cell membranes; both have long used a lipid-saline interface as a physical model of a cell membrane, and the 'electrogenic' effects of acetylcholine on such a system are impressive. Recent advances in our knowledge of the nature of the action potential has, however, convinced most of us that these models can only be regarded as a vast over-simplification of a most complex situation.

F. C. MacIntosh and P. E. Oborin (Montreal) presented what must be the first convincing evidence that acetylcholine is involved in cerebral cortical activity. The acetylcholine released is collected in a small 'Lucite' cup containing eserinized saline placed on the surface of the cortex. Fluid transudes from the cortex into the cup at a rate of about $0.02 \mathrm{ml} . / \mathrm{cm} .{ }^{2} / \mathrm{min}$., and the concentration of acetylcholine in this fluid during light anæsthesia may be as high as $3 \times 10^{-7} \mathrm{gm} . / \mathrm{ml}$. The amount of acetylcholine released is proportional to the electrical activity of the cortex and may be modified by the depth of anæsthesia. The acetylcholine is not derived from parasympathetic vasodilator fibres, and the fluctuation in the amount of acetylcholine released is not accounted for by changes in cerebral blood flow.

Ruth S. Geiger and A. Behar (Jerusalem) described a technique for the growth of neurones in tissue culture. They used grey matter from adult rabbit brain and observed mitosis of neurones in the cultures. Cortisone was more successful than embryo brain extract as an adjuvant to the basic Tyrode's solution and serum mixture; it increased the survival time of individual neurones, prevented the growth of most cells other than neurones, and increased the frequency of mitosis in neurones ten to twenty times.

A. O. Zupancic (Ljubljana, Yugoslavia), who was unfortunately not present, made the suggestion in his abstract that the receptors on cell membranes, to which specific transmitters attach themselves, are one and the same molecules as the enzymes responsible for their destruction. This interesting speculation has many attractions, but seemed somewhat at variance with the findings obtained by 
specific staining for enzymes, which indicate that although the cholinesterase at the end-plates of striated muscle appears to be located at the postsynaptic membrane, the cholinesterase at the ganglion synapses seems to be mainly in the presynaptic terminals.

Turning to fields other than neurophysiological, it was noted, in passing, that C. P. Lyman and D. W. Fawcett (Boston) had shown that exposure to cold of a hibernating mammal (the golden hamster) causes a desaturation of the white fat, whatever the degree of saturation of the dietary fat. This explains how the hibernating animal can maintain its fat stocks in the fluid state, in spite of the fact that fat from animals maintained at $22^{\circ} \mathrm{C}$. is semisolid at $5^{\circ} \mathrm{C}$.

H. E. Essex, H. L. Smith and E. J. Baldes (Rochester) did great service for the average medical student-shades of the ward-round!-in producing a first-rate film (with sound recordings), illustrating beyond reasonable doubt that the first heart sound can be attributed to closure of the mitral and tricuspid valves, and the second to the closure of the aortic valves.

Both D. R. Drury and A. N. Wick (Los Angeles) and R. Levine and M. S. Goldstein (Chicago) read papers supporting the view that the action of insulin in facilitating the metabolism of glucose is due, not so much to a direct effect of insulin upon the responsible enzyme systems but to its effect in promoting the transfer of sugar across the cell membranes, and hence, indirectly, to a more rapid intracellular metabolism.

A whole morning was devoted to papers on glucagon, the hyperglycæmic factor of the pancreas. There has long been scepticism about this 'hormone', but it now appears that it is a real entity. A. Staub, L. Sinn and O. K. Behrens (Indianapolis) described its isolation in crystalline form, and C. de Duve and C. A. Vuylsteke (Louvain) also had achieved a substantial degree of purification. De Duve and Vuylsteke have also improved the assay method using isolated rabbit-liver slices, originally proposed by Sutherland and de Duve. A group meeting on glucagon was also held during the Congress, and it was suggested that the question of standardizing glucagon should be referred to the World Health Organization.

Two group meetings on secretin, organized by M. H. F. Friedman (Philadelphia), were held, and a series of recommendations about the establishment of an international standard for secretin was prepared for submission to the World Health Organization.

D. J. Smith (Burlington, U.S.A.) showed that thyroxine can exert an immediate effect on isolated arteries, increasing their sensitivity to adrenaline by some 250 per cent. The sensitivity of vasa vasorum was even more greatly enhanced by thyroxine. Smith suggested that these effects were due to inhibition of amine oxidase by thyroxine.

R. Carrasco-Formiguera and N. Pi-Sunyer (Caracas, Venezuela) have provided further evidence that the shift in the Arneth count observed in clinical hyperthyroidism, is attributable only to a hypersecretion of thyrotrophic hormone and, like exophthalmos, is not produced directly by thyroxine.

H. C. Meng and Charlotte Hollett (Nashville, U.S.A.) have succeeded in partially separating the anti-coagulant and the lipæmia-clearing activities of heparin by various chemical procedures which reduce the anti-coagulant activity only. The relationship of these findings to the chemical structure of heparin is still unexplained.

Many members of the Congress were interested (and amused) to note that J. Ek and B. Josephson (Stockholm) have found that beer is just as good a diuretic as theophylline-and that this is quite independent of its volume and action in producing a simple water diuresis. The National Health Service in Britain may find even more 'proprietaries' being prescribed as a result.

The symposium on the morning of September 1 on the metabolic influence of insulin was held under the chairmanship of Dr. B. A. Houssay. The principal speakers were F. D. W. Lukens (Philadelphia) on the influence of insulin on protein metabolism; De Witt Stetten (New York) on the inter-relationship of carbohydrate and fat metabolism; F. G. Young (Cambridge) on the interrelationship of pituitary and pancreas; and W. C. Stadie (Philadelphia) on the action of insulin in vitro. These papers were largely reviews of present. day knowledge of these facets of insulin metabolism; but Lukens had fresh evidence to show that carbohydrate in the diet led to nitrogen retention in normal but not in hypophysectomized cats, and Young, that in adrenalectomized animals purified growth hormone exerts a diabetogenic action. Stadie's stimulating paper described experiments in vitro on the binding of insulin by various tissues. Of all tissues examined, only brain failed to bind insulin, and by using insulin labelled with radioactive isotopes of sulphur and iodine, it had been possible to determine insulin in amounts of the order of $0.01 \mu \mathrm{gm}$. Measurements have been made in this way of the effect of insulin upon the synthesis of glycogen in strictly quantitative terms of tissue, substrate and hormone.

In the afternoon, a symposium was held under the chairmanship of Dr. B. Folkow on the hæmodynamics of small vessels. The principal speakers were A. C. Burton (London, Ontario), B. W. Zweifach and D. B. Metz (New York), J. R. Pappenheimer (Boston) and H. Barcroft (London, England). Burton spoke of the structure and function of the elements in the wall of blood vessels ; Zweifach and Metz on the functional behaviour of the terminal vascular bed; Pappenheimer on molecular exchange processes in the capillary circu. lation; and Barcroft on the control of muscle blood flow. Barcroft's contribution, given with typical modesty, was a masterly exposition of what is, and is not, known in this field. The dilatation of the vessels supplying active muscle fibre appears to be entirely accounted for by some change in muscle initiated by the contractile process.

The first of the symposia on September 2 was held under the presidency of Dr. C. F. Schmidt, on reflexes from the cardiac and pulmonary areas. C. Heymans (Ghent) led off with a paper on sinoaortic receptors, in which he reviewed the work on the carotid body, including his own classical and elegant experiments which began in 1924 and are still continuing. O. Krayer (Boston) reviewed the history of the Bezold-Jarisch effect, and was followed by G. S. Dawes (Oxford) on reflexes from the heart and lungs. Dawes attempted a badly needed survey of the many reflexes which have been reported in the literature and appealed for clarity in deseribing them, and for the necessity 
for the adoption of rigid criteria for their classification. He ended with the speculation as to whether many of these reflexes, excited as they are only by drugs, have any useful purpose in normal life. Y. Zottermann (Stockholm) read a paper on electrophysiological investigations of afferent fibres from the carotid sinus region, and made the interesting suggestion that acetylcholine acts as a transmitter of impulses in the carotid body, the glomus cells and the nervous end-plates corresponding to functional synapses. This is a point of lively controversy which has excited discussion for many months. Finally, D. Whitteridge (Edinburgh) discussed the electrophysiology of afferent cardiac and pulmonary fibres, and described new work in his laboratory by Paintal, who has developed an interesting method for the isolation of single small fibres based on conduction-rates. This was, in all, an excellent symposium of papers of a uniformly high standard of excellence.

On the afternoon of September 2, under the presidency of Dr. F. Bremer, a symposium was held on postural mechanisms. This was opened by S. W. Kuffler (Baltimore) on segmental mechanisms, in which he began by assessing our knowledge of posture as rudimentary, and ended on a Sherringtonian note with the conclusion that postural tone is part and parcel of ordinary motility. He was followed by B. R. Kaada (Oslo) on suprasegmental mechanisms. This paper also showed a well-marked integrative action and introduced the role of the labyrinth, the cerebellum and the reticulum. H. W. Magoun (Los Angeles) went on to describe in more detail reticular and striate mechanisms of postural control, and G. Moruzzi (Pisa) rounded off another successful symposium with a paper on cerebellar and cerebral mechanisms. His review was highly technical and somewhat difficult to follow, as indicated by the fact that he cited no less than ninety-five references.

On the morning of September 3, the symposium was on the more general subject of the physiological theories of learning, the chairman being Dr. K. S. Lashley. J. Z. Young (London, England) led off on the learning system of octopus. This work, though lacking somewhat in pristine freshness, is none the less of great importance. R. W. Sperry (Bethesda) continued on regeneration studies and learning, and presented some most interesting data, together with a somewhat rarefied discussion of their physiological, psychological and even philosophical bases. He was followed by K. M. Bykov (Leningrad) on the physiology and pathology of the cerebral cortex. Here again, the rarefied atmosphere of dialectical materialism, coupled with the more mundane difficulties of language, made real insight into his thesis somewhat tricky. The symposium ended with a contribution from A. K. MacIntyre (Dunedin) on synaptic function and learning, which came as a welcome return to the bedrock of electro. physiology.

On the morning of September 4, the symposium was on the mechanism of formation of the thyroid hormone, the chairman being Dr. J. Roche. The principal speakers were E. B. Astwood (Boston) on iodine-collecting mechanisms; R. P. J. Michel (Paris) on the localization and the mechanism of iodination concomitant with the formation of thyroglobulin; E. D. De Robertis (Montevideo) on the physiological hydrolysis of thyroglobulin in the thyroid gland; J. Gross and Rosalind Pitt-
Rivers (New York and London, England) on the passage of tri-iodothyrin and thyroxin into the circulation. Finally, during the afternoon, a symposium was held on the physiology of cold, in which the principal speakers were E. F. DuBois (New York) on the physiology of homoethermic animals exposed to cold; L. P. Dugal (Quebec) on endocrine glands and cold; C. Kayser (Strasbourg) on hibernation in mammals; O. G. Edholm (London, England) on the effect of cold on the circulation of man; and Norma C. C. Kent and N. H. Mackworth (Cambridge) on the effects of cold on human efficiency.

To add to the already bewildering choice of activities that confronted members of the Congress, there were a large number of open, semi-private or private meetings of specialist groups, organized by various private individuals, and held, in the main, concurrently with the official sessions. The largest of these and the only one which it is possible to mention ran as an open meeting for the whole of one day. It was organized by Prof. C. von Euler (Stockholm) on the subject "Biologically Active Polypeptides". It was at this meeting that Van Dyke (New York) announced what was perhaps the most notable scientific advance reported at the Congress, namely, that Du Vigneaud (New York) had succeeded in synthesizing the oxytocic hormone of the posterior pituitary. This is in every way a major advancement, and may well pave the way for further syntheses of biologically active polypeptides.

On September 4, at 5 p.m., a somewhat bedraggled Congress assembled in the Salle de Promotion at the University of Montreal for the closing plenary session. The platform party on this occasion included Cardinal Leger, chancellor of the University of Montreal. Dr. C. H. Best, president of the Congress, offered the thanks of the Congress organizers to all the many Canadians who had helped to make the Congress such a success. After speeches from previous presidents, Dr. Best then announced that the Permanent Committee had accomplished its week's work and that an International Union of Physiological Sciences had been formed. The members of the Council of the new Union are Best (Canada) (chairman), Visscher (U.S.A.) (secretary), Adrian (Great Britain), Bykov (U.S.S.R.), Heymans (Belgium), Houssay (Argentine), Kuno (Japan), Lundsgaard (Denmark), Mayer (France), von Muralt (Switzerland), and Weber (Germany).

Dr. Houssay thanked our Canadian hosts on behalf of all the members of the Congress, and Dr. Best announced that the 1956 Congress would probably be held in Belgium, but that confirmation of the invitation was still awaited.

The plenary session was followed by a special convocation of the University of Montreal at which Cardinal Leger, as chancellor of the University, conferred honorary doctorates in medicine on Dr. E. D. Adrian (Cambridge) and Dr. L. Binet (Paris) (in absentia). Earlier in the week, at a special convocation of McGill University, the Chancellor, Dr. B. C. Gardner, had conferred honorary doctorates of science on Sir Henry Dale, Dr. E. Lundsgaard and Dr. W. R. Hess, all past presidents of Physiological Congresses. This convocation was held in the open air in Molson Stadium. In an address of thanks after the ceremony, Sir Henry Dale made a plea for "complete and confident freedom of communication" among scientists, and declared that national loyalties are not concerned with, and 
need in no way weaken, a common loyalty to the advancement of true knowledge in the sphere of our common interest.

On two evenings during the Congress, members were entertained by the City of Montreal at receptions in the Mountain Chalet on Mount Royal. Mayor Houde was an impressive host, and personally greeted every one of his guests-no mean achievement with a Congress of this size. One afternoon was left free of scientific meetings and was wholly devoted to a programme of excursions in Montreal and its environs.

The Congress proper was followed-with some overlap-by an international meeting of pharmacologists. Two sessions on September 4 were devoted to short communications, and on the following day two symposia were held at MacDonald College. The sun, having baked the physiologists, retired honourably on Saturday, and left the heavens to thunder clouds; the rain which resulted was every bit as whole-hearted as the heat had been. The morning was devoted to a session on the action of drugs at autonomic ganglia, with Dr. J. H. Burn in the chair. Papers were read by W. D. M. Paton (London, England) on types of pharmacological action at autonomic ganglia; R. Wien (London, England) on the relation of chemical structure of compounds to their action at autonomic ganglia; S. Marazzi (Maryland) on the action of adrenaline and the reciprocal action of acetylcholine on autonomic ganglia; N. Ambache (London, England) on autonomic ganglion stimulants; and D. Bovet (Rome) on central effects of ganglionic blocking agents. In the afternoon, the symposium had as its subject the pharmacology of renal tubular mechanisms, and papers were presented by I. Sperber (Uppsala) on competitive metabolism and specificity of renal tubular mechanisms; by J. V. Taggart (Now York) on biochemical features and energy experiments of renal tubular transport; by $\mathbf{K}$. $\mathbf{H}$. Beyer (West Point) on factors basic to the development of useful inhibitors of renal transport mechanisms; by R. W. Berliner (Bethesda) on the effect of drugs on renal tubular transport of hydrogen ions and potassium ions ; and by H. S. Heller (Bristol) on endogenous influences on renal transport mechanisms. The chairman of this symposium was Dr. A. N. Richards.

To bring the week to a fitting and final conclusion the pharmacologists gave a party in Montreal. The gaiety, nowhere more notably evident than in the after-dinner speeches, probably reflected the relief that it was all over. Thus did the tumult and the shouting die, and, in the silent watches of the night, Montreal was deserted by physiologists who crept away to their laboratories in forty-eight different countries of the world. And so to Belgium in 1956. W. L. M. Perry

\section{THE ARMAMENT RESEARCH ESTABLISHMENT}

$\mathrm{T}$ HIS year is being celebrated as the golden jubilee of the oldest organization of its kind in Great Britain, the Armament Research Establishment of the Ministry of Supply. The history of the Establishment is essentially the story of the development of high-explosive munitions as we know them to-day and runs the whole gamut from the lyddite shell and its propellant-the unsatisfactory performance of both of which during the Boer War was largely responsible for the formation of the Establishment-to the atomic bomb.

Previous articles ${ }^{1}$ in Nature have described the work of the Research Department, Woolwich (as the Establishment was then known), from its inception to the end of the First World War, but did not relate how it came into existence. It is proposed to give here a historical review and, so far as security restrictions permit, to describe some of the more important aspects of the Establishment's work since the date of the previous articles. The review will reflect the growing influence of the scientist in matters of defence and the change in emphasis from chemistry to physics in this field.

There existed in 1890 a Government Committee on Explosives, consisting of Sir Frederick Abel (president), Prof. (afterwards Sir) James Dewar and Dr. A. Dupré (all Fellows of the Royal Society). In February of that year this body reported as follows : ". . . the Committee are continually impressed with the great importance, and indeed the necessity, of . . experimental investigations such as are carried on by Col. Sébert, who is one ... of the members of the French Permanent Committee on Explosives, and they venture to urge most strongly the wisdom of so extending the scope of work... of the Government Fxplosives Committee as to add to its members an Artillery Officer having special scientific attainments (such as those possessed by Captain Holden)..." In its final report in 1891, the Committee said: "The Committee on Explosives . . . desire to impress upon those who will pursue this work from the point where they leave it, that unremitting systematic scientific investigation and practical experiment will be absolutely indispensable to the maintenance of that position".

On March 19, 1891, the above-mentioned Captain C. Holden, R.A., sent a memorandum to the Assistant Director of Artillery advocating the setting up of a department "free to carry out experiments only, and not trammelled by proof or other work, which has to be done against time". He pointed out that "the present time, the commencement of a new era, with the introduction of cordite, is an opportune one". As a result of these representations, some years later a small experimental establishment was set up at the Proof Butts at Woolwich. It must be emphasized that this establishment was a military one concerned primarily with ballistics, that is, gun pressures and shot velocities, and that no scientists were employed.

On April 6, 1900, Major F. L. Nathan, Superintendent of the Royal Gunpowder Factory, in a report to the Chief Superintendent of Ordnance Factories, said that he had "ventured to point out to the Director General of Ordnance on 31 March 1900 that our War Office is not abreast of those of foreign powers as regards machinery for systematic study in connection with explosives for military purposes and to suggest to him the desirability of appointing a small committee of experts to direct experiments and researches, and a staff for carrying them out".

On April 12, 1900, the Admiralty wrote to the Under-Secretary of State, War Office, stressing the urgency of obtaining a better propellant than the 